\title{
DEPOIS DE BABEL
}

\author{
Susana Kampff Lages* \\ Universidade Federal Fluminense
}

Mônica Maria Guimarães Savedra** Universidade Federal Fluminense

\author{
Johannes Kretschmer*** \\ Universidade Federal Fluminense
}

O mote para os artigos aqui reunidos é dado pela ideia de que, no espaço literário e cultural de língua portuguesa da contemporaneidade, haveria uma consciência pós-babélica a se impor de diferentes formas a toda e qualquer reflexão sobre línguas, literaturas e

\footnotetext{
* Formação em Letras (Tradutor Intérprete Inglês e Alemão), Pontifícia Universidade Católica do Rio Grande do Sul. Mestrado em Letras, Universidade Federal do Rio Grande do Sul. Doutorado em Comunicação e Semiótica, Pontifícia Universidade Católica de São Paulo. Professora adjunta da Universidade Federal Fluminense, Departamento de Línguas Estrangeiras Modernas - Setor de Alemão. Niterói, Rio de Janeiro, Brasil. E-mail: susanaklages@hotmail.com

** Formação em Português e Alemão, Universidade do Estado do Rio de Janeiro. Mestrado em Educação, Pontifícia Universidade Católica do Rio de Janeiro. Doutorado em Linguiística, Universidade Federal do Rio de Janeiro. Pós-doutorado em Política Linguística, Universität Duisburg-Essen. Professora Adjunta da Universidade Federal Fluminense, Departamento de Línguas Estrangeiras Modernas - Setor de Alemão. Niterói, Rio de Janeiro, Brasil. E-mail:_msavedra@uol.com.br

*** Formação em Letras Românicas e Germânicas, Albert-Ludwigs-Universität Freiburg. Mestrado em Letras Românicas e Germânicas, Albert-Ludwigs-Universität Freiburg. Doutorado em Letras, Universidade do Estado do Rio de Janeiro. Professor da Universidade Federal Fluminense, Departamento de Línguas Estrangeiras Modernas - Setor de Alemão. Niterói, Rio de Janeiro, Brasil. E-mail: johkre@gmx.net
} 
culturas. Tal consciência necessariamente coloca em primeiro plano a tarefa da tradução ou do tradutor, à qual dirigimos nossa reflexão.

À variedade temática dos artigos aqui apresentados subjazem três âmbitos de reflexão específicos: 1) artigos que tratam de entrecruzamentos não apenas entre línguas, mas também da tradução entre diferentes formas de expressão artística, no âmbito das culturas de língua portuguesa; 2) artigos tendencialmente teóricos e centrados na análise de obras de autores portugueses e brasileiros nas quais a ideia da tradução desempenha um papel singular; e finalmente 3) artigos que examinaram de perto procedimentos tradutórios ou que dirigiram sua atenção para o processo de traduzir textos de um contexto linguístico-cultural estrangeiro para um contexto de língua portuguesa, em especial, o brasileiro.

Assim, a relação entre a literatura e outras artes é um dos focos principais de um conjunto consistente de reflexões. A reflexão de Isabel Florêncio Pape sobre a relação entre fotografia e texto em três versões do livro Austerlitz do escritor alemão W.G. Sebald (do original e de duas traduções para o português) destacou o caráter utópico do ato de traduzir como inscrito também em signos visuais. Segundo outro estudo, de autoria de Rosana Kohl Bines, a descrição de telas de Balthus em um conto de Sergio Sant'Anna evidencia os limites das expressões linguísticas, e ao mesmo tempo permite pensar o topos da infância como zona liminar, operadora de passagens entre silêncio e linguagem, inconsciência e consciência. Além da pintura, a literatura dialoga também com a fotografia: a aura identificada por Walter Benjamin na primeira fase da fotografia pode ser reconstruída pelo observador em obras contemporâneas, seja de modo intencional, como em Struh, seja por assim dizer a contrapelo, como nas fotografias de Carlos Goldgrub, examinadas no artigo de Ulrich Johannes Beil.

Os artigos sobre escritores de língua alemã do século $\mathrm{XX}$ demonstram outras dimensões de traduzibilidade: Maria Aparecida Barbosa discorre sobre a utopia ecológica de um ideal sustentável na arte, tal como concebida por Kurt Schwitters, o que lhe possibilita debater também práticas de artistas brasileiros. E a tradução 
de peças de teatro de Franz Xaver Kroetz representa um desafio à tradução que vai além da questão do dialeto: Werner Heidermann nos propõe a questão de como traduzir para o público brasileiro os dramas de uma sociedade profundamente pequeno-burguesa, moldados numa variedade linguística bastante idiossincrática. Ainda no âmbito austríaco, o artigo de Luis Sergio Krausz focaliza um folhetim jornalístico do escritor Joseph Roth que trata de uma miniatura do Templo de Salomão por ele encontrada no bairro judeu de Viena. Esse achado traduz de modo significativo sua nostalgia pelo império Austro-Húngaro e por antigas crenças do judaísmo tradicional, igualmente em vias de desaparecer.

Outra reflexão instigante sobre a força da língua, o artigo de Luciana Villas Bôas examina o poder da língua à luz de uma investigação sobre a língua do poder na época da expansão portuguesa e nos relatos do Brasil colonial. A força da língua em sua materialidade também se faz presente nos trabalhos que tratam da obra de autores da modernidade literária de língua portuguesa, tais como Fernando Pessoa, João Guimarães Rosa, Haroldo de Campos e Herberto Helder. A partir da análise de um poema de Fernando Pessoa, Paulo Henriques Britto defende a necessidade de se identificar o contraponto rítmico - um intrincado entrelaçamento entre dimensão semântica e formal - para que a tradução competente de poesia seja possível. O estudo de Joachim Michael demonstra como a obra de Pessoa tradutor do inglês e do francês serve como paradigma de movimentos translacionais que se confundem com sua moderna proposta de afirmação da figura de um autor que se desdobra em muitos, da heteronímia constitutiva de sua obra.

Em poetas de certa forma pós-pessoanos, como o brasileiro Haroldo de Campos e o português Herberto Helder, a tradução segue por outras trilhas, não menos inventivas: No estudo de Andrea Lombardi, o trabalho de transcriação poética de Haroldo de Campos é apresentado como resultado de uma leitura da língua de Dante e sua relação com a poesia do dolce stil novo, convertendo, numa dramatização das origens da lírica ocidental, o Amor provençal-trovadoresco em luz de origem bíblica, luciferina, ou seja, em emblema da própria empresa 
de tradução como criação. Já o estudo de Sabrina Sedlmayer elege outra via para afirmar a tradução como exercício poético criativo, no qual Herberto Helder faz com que se encontrem na constelação do livro as "vozes comunicantes" de línguas desaparecidas ou em vias de desaparecimento, do texto bíblico, de poetas da modernidade, surrealistas, marginais, em cujo seio lucidez e desvario se mesclam. A tradução como comunicação enigmática e truncada, de uma parte, e potência reveladora e iluminadora de sentidos ocultos, por outra, foi objeto do estudo sobre a novela "Recado do morro", de João Guimarães Rosa, de autoria de Susana Kampff Lages.

Estudos de caráter mais marcadamente teórico centraram-se em aspectos fulcrais da transmissão entre línguas e culturas: o trabalho de Márcio Seligmann-Silva sobre o papel da tradução na teoria de Vilém Flusser reitera a dimensão criativa da obra do tradutor, tanto maior numa época em que o predomínio das imagens técnicas obriga à superação do paradigma identitário tradicional, tributário da tradição romântica e pós-romântica, aproximando cada vez mais a tarefa do tradutor à do artista criador; outro aspecto fundamental para se pensar o traduzir é focalizado pela reflexão de Mauricio Mendonça Cardozo sobre as múltiplas implicações da idéia de $r e-$ lação, ao investigar as aporias geradas pelo caráter singularmente relacional do traduzir a partir da obra de E. Lévinas e J. Derrida. Fundamental também é o estudo de Heike Muranyi, que examina a forma como a obra de Paulo Rónai acaba por se constituir em parte de sua própria biografia intelectual, graças à íntima relação que ele estabelece entre a profissão de tradutor e a própria vivência translatícia de intelectual húngaro exilado no Brasil.

Finalmente, um bom número de artigos apresentados parte das implicações interculturais no processo de traduzir para ou da língua portuguesa, com foco na tradução de literatura em contextos coloniais e, sobretudo, pós-coloniais na contemporaneidade. Aqui, a tradução não é vista apenas como processo interlingual, mas, sobretudo, como atividade intercultural. Nos espaços culturais de língua portuguesa, problemáticas tipicamente pós-coloniais aparecem em traduções de literatura afro-americana contemporânea do inglês para 
o português do Brasil e vice-versa, nas quais a construção de identidades em diferentes contextos geográficos e culturais é questionada, como nos mostra o estudo de Maria Aparecida Andrade Salgueiro.

A reflexão de Luiz Barros Montez destaca a importância de se considerar os relatos de viagem como campo discursivo singular que suscita reflexões de caráter historiográfico, evidenciando a necessidade de o tradutor levar em conta a inscrição histórica dos textos a serem traduzidos. Finalmente, no âmbito de estudos linguísticos contrastivos, apresentamos um interessante estudo, assinado por Mônica Maria Guimarães Savedra e Marina Dupré Lobato, sobre os aspectos de tempo, modo e aspecto na escolha das formas verbais em traduções de obras contemporâneas da língua alemã para a língua portuguesa na variedade brasileira e vice-versa, o que evidencia mais uma vez a importância da apreciação contrastiva de elementos não apenas linguísticos, mas também culturais. A diversidade temática e as diferentes abordagens ao problema da tradução aqui apresentadas oferecem ao leitor interessado na tradução como problema lingüístico, cultural e também, epistemológico e estético, instigantes questionamentos.

Por fim, os organizadores do presente volume desejam expressar seu agradecimento à editora-chefe da revista Cadernos de Tra$d u c ̧ a ̃ o$ e a todas as agências de fomento e instituições brasileiras (CAPES, CNPq, FAPERJ, FAPESP, e às universidades UFMG, PUC-Rio e UFF), austríacas (Universidade de Viena) e alemãs (DAAD, DFG) que contribuíram com o fomento que resultou nos artigos da presente publicação. 